\title{
Alzheimer's Disease: Future Efforts to Thwart Memory Loss
}

\author{
Herbert B Allen* \\ Department of Dermatology, USA
}

*Corresponding author: Herbert B Allen, Professor and Chair Emeritus, Drexel University College of Medicine, Department of

Dermatology, 112 White Horse Pike, Haddon Heights, NJ 08003, USA

\begin{tabular}{|c|c|}
\hline ARTICLE INFO & ABSTRACT \\
\hline Received: 蔧 October 25, 2019 & During the past few years, Alzheimer's disease (AD) has been shown to be a chronic \\
\hline Published: 幽 October 30, 2019 & $\begin{array}{l}\text { infection. Spirochetes, Lyme Borrelia and dental treponemes, are the etiologic agents; } \\
\text { these spirochetes make biofilms, and, in so doing, are responsible for the formation }\end{array}$ \\
\hline $\begin{array}{l}\text { Citation: Herbert B Allen. Alzheimer's } \\
\text { Disease: Future Efforts to Thwart Memory } \\
\text { Loss. Biomed J Sci \& Tech Res 22(2)-2019. } \\
\text { BJSTR. MS.ID.003738. }\end{array}$ & $\begin{array}{l}\text { of beta amyloid and hyperphosphorylated tau protein. The pathways for all these } \\
\text { components of AD has been outlined. The following are possible future efforts based } \\
\text { on the above information. These include attempting to culture the dental spirochetes as } \\
\text { well as attempting to develop a serologic test for pre-AD. A trial for early AD is proposed, } \\
\text { as is a possible way of preventing AD with periodic courses of effective antibiotics. }\end{array}$ \\
\hline
\end{tabular}

Abbreviations: AD: Alzheimer's Disease; PCR: Polymerase Chain Reaction; GP: General Paresis; ABPP: Abeta Precursor Protein

\section{Commentary}

It has been shown recently that Alzheimer's disease (AD) is a chronic infectious disease with the causative microbe being a spirochete. Lyme (Borrelial) spirochetes have been cultured from affected brains, and, they and dental spirochetes (various treponemata) have been found by polymerase chain reaction (PCR) [1-3]. Further, the infection has been shown to satisfy Koch-Hill postulates relating to, and firmly establishing, its infectious nature [2]. The spirochetes have been visualized pathologically and have been shown to create pathological changes similar, in every way, to those seen in another spirochetal disease, syphilitic dementia, which is termed general paresis (GP) [4]. Further, no coccobacillary forms and no viral changes have been noted in the pathology specimens examined. The pathology of AD is strictly "helical".

The spirochetes form biofilms like most other microbes; and, in large measure, the biofilms contribute to the chronicity of the disease [5]. Once in a biofilm, the microbes become resistant to antibiotics and to both arms of the immune system, innate and adaptive. In the extracellular space, the biofilms attract Toll-like receptor 2 (they have receptor sites for this molecule), and, by known pathways (MyD88 and NFkB), this interaction leads to the production of beta amyloid (Abeta) [6,7]. The Abeta, which is also anti-microbial, cannot penetrate the biofilm, just like antibiotics, and it has been shown that it encases the biofilm without engaging the spirochetes within [7]. The spirochetes also make biofilms intracellularly, and somewhat surprisingly, make Abeta precursor protein (ABPP) and Abeta simultaneously $[8,9]$. This process has been demonstrated both in vitro and in vivo. It has also been discovered recently that Abeta in contact with tau protein causes the tau protein to become phosphorylated, and it no longer functions as a dendrite stabilizer leading to dendrite and cell collapse $[10,11]$. With that, the neuron is no longer functional. With this as background, the contemplated future actions related to this hypothesis, are at least five in number:

a. Popularize the concept of a bacterial origin for AD.

b. Culture the dental spirochetes.

c. Develop a serologic test that would identify AD before it is clinically apparent similar to the RPR in GP (tertiary syphilis).

d. Treat with penicillin or another bactericidal antibiotic for three weeks once yearly.

e. Initiate a clinical trial in mild cognitive impairment (MCI) to discern whether the disease progression can be stopped or slowed. Each of these 5 will be discussed further in the following. 
For the past twenty-five years, the beta amyloid causation of $\mathrm{AD}$ has been predominant. This is understandable because this molecule is abundant in affected brains. However, as it has been shown, the microbes make Abeta while they are in the process of making biofilms [9]; further, the response of the innate immune system to the biofilms also creates Abeta. Thus, its creation is largely dependent on the microbes making biofilms. P-tau has recently been implicated in causing AD. As has been previously outlined, this is also directly related to the microbes making biofilms. The Abeta, which is produced at the same time as the biofilms, interacts with tau protein and converts it to $\mathrm{p}$-tau $[10,11]$. Thus, $\mathrm{p}$-tau is also largely dependent on the microbes making biofilms. When Lister made his monumental discovery about microbes causing the incredible suppuration rates after surgery and a way to prevent it, it took 20 years before the concept became widely known and practiced. His method for disseminating the information was by teaching students (he taught hundreds) and by writing about it. Fortunately, the British Medical Journal was receptive to his findings and became the beacon for the discovery [12]. Once the current concept gains traction, there are many more ways of disseminating information than were available to Lister. AD is such a catastrophe in human and financial terms that all the modalities for transmission of microbial nature of this dreaded disease should be employed. Culturing the oral spirochetes would be a useful undertaking. Treponema, in general and T. pallidum (syphilis) in particular, have evaded being cultivated. However, very recently, T. pallidum has apparently been cultured [13].

With similar techniques, it may be possible to culture the many dental spirochetes. T. pallidum takes considerable time to divide (as much as 3 months) and this may be one of the difficulties in getting it into culture. The serologic test for syphilis, together with penicillin treatment for positive tests, has relegated tertiary syphilis, including GP, to history. That disease has been eradicated. Currently, there is a microarray test for MCI, or early AD [14]. Perhaps this test can be modified to include pre-AD; such an alteration would lead to treatment before the disease begins, which is crucial. Treatment after the disease begins is fraught with difficulty, as is documented by 200 failed clinical trials in disease that has already begun. This fits with the pathology showing nearly all the neurons in the $\mathrm{AD}$ patients filled with biofilms. Until a serologic test is available, it is reasonable to consider treating with yearly penicillin (ex. Amoxicillin 500mg tid x 3 weeks) which would very likely prevent the disease. Penicillin crosses the blood brain barrier and the neuronal cell membrane and is bactericidal to sensitive microbes. All spirochetes are sensitive to penicillin. Consequently, a yearly course of penicillin would most likely kill the spirochetes prior to their making biofilms. This correlates with its treatment in GP; if penicillin is given anytime prior to the onset of dementia, this disease would be prevented, just as GP has been prevented. Again, where GP and AD have the same pathology, one would expect these results with similar treatment.
The reason for yearly treatment is the constant seeding of dental microbes, as opposed to one time exposure to T. pallidum in syphilis. As to resistance, it is likely that less resistance would be forthcoming with this regimen because microbes inside biofilms trade resistance genes horizontally which increases resistance. It is apparent that spirochetes by themselves (planktonic) do not cause the disease; it is when they form communities that they assume pathogenicity. Alternative therapies include Penicillin VK 500mg qid, or for penicillin allergic, Azithromycin 500mg bid x 1 week then 500mg per day x 2 weeks. For penicillin regimens, adding probenecid $500 \mathrm{mg}$ tid doubles the serum concentration because it decreases renal excretion. When, and if, benzathine penicillin becomes more available, it is a better option because it, plus or minus probenecid, does not require patient compliance with the treatment regimen. It is unclear whether any treatment will stall or prevent progression of the disease. This is a place where a clinical trial would potentially be helpful. The arms of the trial would be any current regimen, such as memantine vs amoxicillin/azithromycin plus rifampin $300 \mathrm{mg}$ daily. The active arm of the trial includes both the antibiotic and a known biofilm disperser (rifampin) [15]. This regimen would likely need to be continued for many months. A trial prior to the onset of the disease, would hardly be ethical, because the control arm would get AD if the microbes were unopposed.

\section{References}

1. Mac Donald AB (1986) Borrelia in the Brains of Patients Dying with Dementia. JAMA 256(16): 2195-2196.

2. Miklossy J (2011) Alzheimer's Disease-A Neurospirochetosis. Analysis of the Evidence following Koch's and Hill's Criteria. Journal of Neuroinflammation 8: 90 .

3. Riviere GR, Riviere GH, Smith KS (2002) Molecular and immunological evidence of oral treponemes in the human brain and their association with Alzheimer's disease. Oral Microbiol Immunol 17(2): 113-118.

4. Miklossy J (2015) Historic evidence to support a causal relationship between spirochetal infections and Alzheimer's disease. Front Aging Neurosci 7: 46.

5. Allen HB (2019) The Essential Role of Biofilms in Alzheimer's Disease. Microbiol Infect Dis 3(2): 1-3.

6. Tukel C, Wilson RP, Nishimori M, Pezeshki M, Chromy BA, et al. (2009) Responses to Amyloids of Microbial and Host Origin are mediated through Toll-like Receptor 2. Cell Host Microbe 6(1): 45-53.

7. Allen HB (2016) Alzheimer's disease: Assessing the Role of Spirochetes, Biofilms, the Immune System, and Beta Amyloid with regard to potential Treatment and Prevention. J Alz Dis 53(4): 1271-1276.

8. Allen HB, Allawh R, Touati A, Katsetos C, Joshi SG (2017) Alzheimer's Disease: The Novel Finding of Intracellular Biofilms. J Neuroinfect Dis 8: 247.

9. Miklossy J (2016) Bacterial Amyloid and DNA are Important Constituents of Senile Plaques: Further Evidence of the Spirochetal and Biofilm Nature of Senile Plaques. J Alz Dis 53(4): 1479-1473.

10. Iqbal K, Alonso AC, Chen S, Chohan MO, El Akkad E, et al. (2005) Tau pathology in Alzheimer disease and other tauopathies. Biochim Biophys Acta $1739(2-3):$ 198-210

11. Zempel H, Thies E, Mandelkow E, Mandelkow EM (2010) A $\beta$ Oligomers Cause Localized Ca2+ Elevation, Missorting of Endogenous Tau into Dendrites, Tau Phosphorylation, and Destruction of Microtubules and Spines. J Neurosci 30(36): 11938-11950. 
12. Fitzharris L (2017) The Butchering Art. Penguin Random House UK London.

13. Edmonson DG, Hu B, Norris SJ (2018) Long-Term In Vitro Culture of the Syphilis Spirochete Treponema pallidum subsp. Pallidum 9(3): e011531218.

14. De Marshall C, Nagele EP, Sarker A, Goldwaser EL, Kosciuk M, et al. (2016) Detection of Alzheimer's disease at mild cognitive impairment

ISSN: 2574-1241

DOI: $10.26717 /$ BJSTR.2019.22.003738

Herbert B Allen. Biomed J Sci \& Tech Res

(c) (i) This work is licensed under Creative

Submission Link: https://biomedres.us/submit-manuscript.php and disease progression on using autoantibodies as blood-based biomarkers. Alzheimer's and Dementia 3: 51-62.

15.Zheng Z, Stewart PS (2002) Penetration of Rifampin through Staphylococcus epidermidis Biofilms. Antimicrob. Agents Chemother 46(3): 900-903.

$\begin{array}{ll}\text { BIOMEDICAL } & \text { Assets of Publishing with us } \\ \text { RESEARCHES } & \text { - Global archiving of articles } \\ & \text { - Immediate, unrestricted online access } \\ & \text { - Rigorous Peer Review Process } \\ \end{array}$

